\title{
O CASO DO PSICODIAGNÓSTICO: UM ESTUDO INSTITUCIONAL
}

\author{
Marlene Guirado ${ }^{1}$ \\ Instituto de Psicologia - USP
}

O psicodiagnóstico é uma prática recorrente de estudo de caso em Psicologia, independentemente de ser feito em consultórios particulares, escolas, hospitais, ambulatórios e/ou instituições para-educativas. O presente artigo discute a dimensão institucional desse atendimento na medida em que se trata de um dispositivo que, cada vez mais, legitima seu objeto: o conhecimento do psiquismo de quem se expõe aos serviços do psicólogo. Tal discussão parte do destaque de conceitos como discurso, sujeito, instituição e análise, tomados nos terrenos da Psicanálise e da análise de instituições concretas, para configurar uma possibilidade de estudo de caso que considere o contexto institucional do (ou, em que se fez o) diagnóstico. Por fim, faz-se uma proposta de como proceder a um estudo de caso que suponha a força constitutiva desse contexto sobre o resultado do psicodiagnóstico de um cliente/paciente do psicólogo.

Descritores: Psicodiagnóstico. Processos psicoterapêuticos. Instituições de saúde.

Tós, psicólogos, somos freqüentemente solicitados a (e nos consideramos capacitados para) fazer psicodiagnósticos. Reveste-se essa ativicaso. No entanto, o que se costuma assim produzir é um estudo psicológico daquele que se nos apresentou como cliente, por ele mesmo ou por algum responsável. Entrevistas e procedimentos que vão da aplicação de testes até

1 Psicóloga, Psicanalista, Analista Institucional e Docente do Instituto de Psicologia - USP. Endereço eletrônico: mguirado@terra.com.br 


\section{Marlene Guirado}

a "caixa de ludo" ou seus equivalentes (por se tratar de uma situação menos estruturada do que aquela prevista para os testes), para jovens e adultos, constituem a fonte de material reunido para uma análise que, por sua vez, vai também das interpretações padronizadas até as alinhadas a recursos teóricos das psicanálises que conhecemos e praticamos.

O que marca esses dispositivos de orientação ora mais ora menos psicanalítica é a suposição de que alguém se expõe a (e precisa de) uma análise e outro alguém, especializado no assunto, se dispõe (e pode) analisá-lo. Toda a cena diagnóstica se constrói, portanto, em função da crença de que duas pessoas mediadas por um recurso técnico podem chegar à verdade a respeito de o que provoca o distúrbio e/ou o sofrimento de uma delas. Alguém conhece (porque pode fazê-lo) outro alguém (que não dispõe de recurso especializado para se conhecer), com o recurso de uma técnica, numa relação de justaposição de partes: um alguém, o outro alguém e o recurso técnico. Numa relação parte-extra-parte, portanto.

Convém dizer que não estamos aqui afirmando que só os psicodiagnósticos procedem desta maneira. Um acompanhamento mais atento, e a partir de um outro ponto de vista, nos levaria a dizer igualmente dos atendimentos psicanalíticos, nos consultórios bem como em instituições outras onde se exerça a psicanálise como produção de conhecimento e da clínica ${ }^{2}$. Atestam-no os inúmeros estudos que temos desenvolvido, na qualidade de autora e de orientadora (Galvão, 2000; Guirado, 1995, 2000; Lerner, 1999; Souza, 2003; Vechi, 2002; Veiga, 2000).

É que, por esse outro ponto de vista que doravante nos propomos a apresentar, toma-se o atendimento psicológico como fazer instituído e, com isso, toma-se a relação profissional-cliente como atravessada e sustentada numa rede de expectativas entre os parceiros, de tal forma que seria impossível imaginá-los numa justaposição e/ou “ligados” por um recurso metodológico.

2 Importa ressaltar que a referência à Psicanálise deve-se ao fato de, normalmente, os psicodiagósticos terem essa orientação. Isto não quer dizer que apenas a Psicanálise busque verdades e se exerça numa relação parte-extra-parte. 


\section{O Caso do Psicodiagnóstico: um Estudo Institucional}

Nosso pressuposto é o de que essa é a marca das instituições: um efeito de reconhecimento/desconhecimento "naturaliza” nosso fazer, ou seja, atribui um estatuto de legitimidade aos procedimentos e esses não se dão fora dos dispositivos discursivos que o constituem. É no plano do discurso também entendido a partir de agora como ato, como procedimentos que tecem concretamente as palavras e as idéias- que se definem as expectativas, as verdades, as apropriações dos direitos de fala e das posições.

Não nos precipitemos, no entanto, porque aí se fundam as diferenças entre o que habitualmente se diz ser um estudo psicodiagnóstico de caso e o que ora propomos como um estudo institucional... de caso.

\section{O lugar do conceito no discurso do método}

É importante começar tratando do contexto teórico-epistemológico que tece a presente proposta. Ou seja, é importante precisar a estratégia de pensamento que justifica falar de um estudo institucional de caso, do e no atendimento psicológico.

Cada palavra, aí, foi intencionalmente posicionada: o estudo é que considera as implicações de um atendimento ser feito no brique-braque dos procedimentos, sempre atos discursivos, de uma ou mais instituições. $\mathrm{O}$ foco, portanto, recai sobre a ocasião de um atendimento específico, um "caso”, como se costuma dizer. E não, sobre o conjunto das relações institucionais. Esta direção, porém, inevitavelmente considerará o enlaçamento das práticas, das relações em que o diagnóstico se faz. Aliás, será esta a marca distintiva de tal modo de operar. Ao estudar o específico, considerar como o conjunto das práticas institucionais o constitui.

Assim se define, então, o método, conforme o subtítulo acima: um dispositivo a supor conceitos que distribuem sentidos particulares aos procedimentos, que são sempre práticas discursivas, à sombra dos quais se produzem resultados, ou melhor, diagnósticos. 


\section{Marlene Guirado}

O que há de mais perturbador em tal afirmação é que o que resulta, na qualidade de um psicodiagnóstico, está, até certo ponto, datado e assinado, pelo discurso das instituições em jogo. As variações são também constitutivas dessa situação. No entanto, elas dependem exclusivamente de serem assumidas posições que resistam a afirmar o resultado como conhecimento da realidade psíquica do sujeito (de uma pessoa, para sermos mais precisos), excluindo outras possibilidades de considerá-la; dependem de resistir, como diria Foucault, à vontade de verdade da ordem do discurso; dependem de colocar em suspensão as significações não mediatizadas por essa ordem, bem como a "soberania do significante” (Foucault, 1970/1996).

Pensar desse modo faz, necessariamente, supor que o resultado de um psicodiagnóstico, de um jeito ou de outro, está implicado na perspectiva dos recursos mesmos de avaliação. Diz deles, sobretudo, e não, propriamente da pessoa que foi diagnosticada, isto é, de sua realidade psíquica. Pensar desse modo, ainda, faz supor que tal ordem do discurso, exceto nas ocasiões em que nos dispomos declaradamente a resisti-la, exerce-se a cada reinstauração do procedimento, do ato, da relação que assim se institui, articulando efeitos de reconhecimento e desconhecimento, ao arrepio de nossas mais bem intencionadas consciências, exatamente ali onde supomos produzir conhecimento.

Se eu dissesse logo de início que o método determina o resultado, com certeza pareceria repetir algo que, às cabeças mais ilustradas, pareceria óbvio. No entanto, o enredamento dos efeitos de reconhecimento e desconhecimento das relações e/ou práticas de conhecer, avaliar, pesquisar, que insidiosamente nelas e por elas se produz, permaneceria o ponto cego a depor contra nossos mais sérios propósitos de bem conhecer. O mais desconhecido em nossas práticas, ainda que bem intencionadas, é o como se faz a naturalização do instituído.

As teorias são o locus preferente para a reprodução de pontos cegos. Elas recebem normalmente os créditos de verdade e confiança daqueles que com elas operam. Porto seguro nas tempestades de nossos habituais (des)entendimentos, como num passe de mágica, transformam-se em depo- 


\section{O Caso do Psicodiagnóstico: um Estudo Institucional}

sitários de nossa vontade de verdade. Costumamos pensar que nós podemos errar, mas a teoria que abraçamos é o que há de mais certo. Mas, em realidade, são elas que, ao fim e ao cabo, confrontamos como produto do conhecimento. Trata-se, aqui, de negá-las, rechaçá-las, produzir sem elas? Não. Até porque isto seria impossível. Como funcionar, então, sem cair no relativismo absoluto, que, como absoluto, voltaria a negar a ordem discursiva e sua "temível materialidade”? (Foucault, 1970/1996).

A idéia é definir, ou melhor, afirmar, de ponto de partida, o campo conceitual que organiza a estratégia da análise produzida; mais especificamente, a avaliação ou a pesquisa em curso.

É isto que faremos agora para melhor fazer entender o que chamamos de estudo institucional de um caso ou de um atendimento.

\section{Em Foucault e Freud, as matrizes conceituais}

O leitor versado em qualquer um dos dois autores poderá, de início, "torcer o nariz" diante dessa proposta de aproximação de dois modos de pensar tão distintos. De certa forma, tem razão. Mas se me acompanhar em todas as passagens para a construção da proposta, verá que ela tem chance de se sustentar.

O exercício de buscar aproximações começa com a demarcação das diferenças ou especificidades de cada um dos referentes: só assim será possível proceder a articulações. Estas passarão a organizar um outro modo de proceder, um outro dispositivo discursivo e conceitual que não será mais o primeiro e sequer o segundo. No entanto, sem as matrizes teria sido impossível construí-lo.

Na psicanálise de Freud, destaca-se o princípio da singularidade do sujeito que nos fala, a reeditar, sem consciência do ato, numa situação presente, modelos de relação vividas no passado; melhor: repetindo a posição que se “viu” ocupando, desde lá e então; movendo-se na transferência. 


\section{Marlene Guirado}

Sabemos que, cada um e todos, esses termos ganham, com a Psicanálise, um sentido próprio ao campo desse conhecimento que configura como sujeito singular da fala, das representações e/ou fantasias e afetos inconscientes, um sujeito que se determina pelos movimentos de pulsões de vida e de morte, sexualidade e destruição; um sujeito que, por extensão narcísica de forças pulsionais, constrói-se na interface com as exigências que lhe faz o meio; assim, a sobrevivência, para que se garanta, precisa da relação tanto quanto da endogenia das forças pulsionais (Birman, 1999; Freud, 1930/1969; Guirado, 1995, 2000). Esta é a subjetividade freudiana.

Ao bom entendedor, cria-se, então, um impasse (e não um caminho de passagem) para o terreno do pensamento foucaultiano. Mas é necessário prosseguir...

Em Foucault, destaca-se, na ordem de sua produção teórica, o conceito de discurso como ato, acontecimento, como dispositivo produtor de sujeitos, na radial oposição do si interior e autóctone da psicanálise. O si de Foucault é uma objetivação das práticas discursivas e estas, por sua vez, são um conjunto de regras mais ou menos estáveis para uma determinada época, para um determinado lugar geográfico, e para regiões da produção humana, cujo efeito fundamental é estabelecer separações entre o falso e o verdadeiro, excluindo como teratologia do saber, o que não se pode dizer nessa ordem (Foucault, 1979, 1970/1996, 1988/1990). A fala de alguém, portanto, não se pauta por motivos de ordem interior, mas exterior, contextual. A idéia de sujeito e de subjetividade guarda essa dimensão de construção histórica, por e nos dispositivos institucional-discursivos.

A lingüística, a partir da década de 1970, apropriou-se, sobretudo, da idéia foucaultiana de discurso como ato. Como nos ensina Dominique Maingueneau, um ramo da lingüística contemporânea - a Análise do Discurso Francesa- apostou na força da teoria da enunciação e passou a operar suas análises, destacando a fala não como a expressão de um sujeito em particular, sequer da realidade fora dele, mas como a legitimação da posição do falante e do seu direito de dizer: todo texto só se pode considerar enlaçado ao contexto de sua produção que é ocasião de expectativas em relação ao 
que se tem como interlocutor. O conceito de Gênero Discursivo, que não se confunde com o de estilo de linguagem, é a base para a análise que indicará, assim, as cenas enunciativas e os sentidos mostrados no dizer (Guirado, 2000; Maingueneau, 1989, 1997).

De outro ponto, a sociologia, outras apropriações das idéias de Foucault vão se anunciar: a Análise de Instituições Concretas, de Guilhon Albuquerque (1978), é uma delas. Daí depreende-se o conceito de instituição como prática social que se repete e nisso legitima-se, sendo reconhecida por quem a faz como "natural”, como tendo que ser do jeito que é; desconhecendo-se, no mesmo ato, a relatividade ao contexto, bem como o caráter instituído das relações, sempre datadas e historicamente construídas.

Como se pode notar, parece que se ganhou uma distância absoluta dos pressupostos psicanalíticos. É que eles precisarão sofrer uma espécie de giro, de releitura, como se costuma dizer, para que possamos dar conta de nossa tarefa de demonstrar a viabilidade da proposta de uma certa estratégia de pensamento a instrumentar quer as análises, quer as avaliações, quer os psicodiagnósticos, numa perspectiva que considere o dispositivo mesmo desse fazer do psicólogo.

\section{A migração dos conceitos para um novo campo}

As releituras criam, a seu modo, um enredamento do texto ou da teoria em foco, numa malha conceitual que exige muita atenção, para que não se façam transposições imediatas de sentido. No nosso caso, portanto, todo cuidado será pouco ao tratar dos termos si, singularidade e sentido, deslocados de seu nichos teóricos para um outro que se pretenda instaurar em suas fronteiras.

Trabalhemos, então, uma situação exemplar desse movimento ou migração de um conceito: como entender a singularidade na proposta que ora buscamos apresentar? 


\section{Marlene Guirado}

Aliás, a pergunta sobre a singularidade, travestida de várias roupagens em função dos diferentes contextos onde é feita, parece ser aquela que não quer calar em nossa cultura. Talvez porque só nessa cultura teria algum sentido. Ou, como diria Foucault, só numa determinada ordem de discurso poderia ser formulada. Mas o fato é que, do senso comum à pesquisa acadêmica, em Psicologia Social ou Psicanálise, por exemplo, clama-se pela especialidade do um, apesar de todo discurso da determinação grupal ou social do indivíduo, como se costuma dizer.

Acompanhemos duas situações prosaicas, a título de esclarecimento dessa preocupação.

A primeira: aquele renomado (e obviamente hipotético) especialista em adolescência, ou em problemas sociais e sócio-afetivos, acabou de fazer palestra sobre o uso de drogas no quarto do filho (de casais que ali estavam por absoluto interesse em resolver sérias questões familiares ) e a relação disso com a indústria da droga, com o crime organizado do narcotráfico que, em breve se descobriria, tem vocação para constituir partidos políticos que perversamente defenderiam suas causas. Da platéia, vem a primeira interpelação, de quem ouviu tudo, mas permaneceu com a angústia de buscar explicações “mais subjetivas”, ou diferenciadoras de individualidades: porque uns adolescentes aderem ao uso de drogas e outros não? Nem precisamos continuar descrevendo a cena; podemos garantir que qualquer resposta, nessa situação, iria exigir uma espécie de salto no teor da fala que até então vinha se pronunciando. E mais: torcemos para que o palestrante não pule, no escuro de uma passagem abrupta, para determinações estritamente psicológicas que dispensem a consideração de aspectos sociais mencionados, tão evidentemente relevantes, no que diz respeito à questão do consumo de drogas na atualidade.

Em outro contexto, ainda hipotético, um estudioso de Psicanálise resolve fazer sua tese de mestrado ou doutorado e defronta-se com o impasse de como fazer chegar até lá, sua clínica. Parecem-lhe dois mundos radicalmente distintos, o de produzir um trabalho acadêmico e o de atender seus pacientes no consultório. E, de fato, instaura-se um abismo entre a fala inti- 


\section{O Caso do Psicodiagnóstico: um Estudo Institucional}

mista de um cliente em sessão, protótipo de singularidade, e o discurso/procedimentos exigidos para o trabalho de comunicação intelectual e de pesquisa, conforme os cânones da universidade. Muito provavelmente, o pesquisador escolha um entre dois caminhos, os únicos que se lhe parecem possíveis: abandona a perspectiva clínica e, com isso, sacrifica a inspiradora singularidade de seus casos; ou então, decide preservar relatos tão particulares e se desculpa, no capítulo sobre a metodologia, pela perda de cientificidade.

No contexto, agora já não mais imaginário, deste nosso texto com vistas a produzir na fronteira dos sentidos atribuídos aos termos em diferentes redes conceituais, recolocamos a questão. Sobram razões para tanto e é preciso tentar respostas se quisermos argumentar nossa proposta. Então, como entendemos a singularidade? Como uma organização particular da subjetivação de que os dispositivos institucionais discursivos são ocasião. Em outro momento, para poder falar com mais liberdade sobre o assunto (Guirado, 1995), construímos uma metáfora, a de um Sujeito Dobradiça. Um conceito dobradiça de sujeito. Assim foi possível falar de uma subjetividade efeito com matizes singulares, na medida em que há uma organização particular de toda uma história de relações, construída vida a dentro (ou, vida a fora), com sede, ali, onde costumamos ver e nomear o sujeito psíquico. Um sujeitoorganizador dos incontáveis e insidiosos efeitos de reconhecimentos e desconhecimentos das relações vividas.

À margem, portanto, de um sujeito estritamente endógeno e pulsional, característico do discurso psicanalítico, bem como à margem do sujeito universal da lingüística ou do sujeito-grupo da Sociologia, e suportados pela idéia de subjetivação, acabamos por produzir no exato ponto de tensão das inalienáveis contribuições de Freud, Foucault, Maingueneau e Guilhon Albuquerque; no ponto de tensão de conceitos por eles formulados. Daí, a referida metáfora de um modo de dizer dos processos de subjetivação: o sujeitodobradiça é a possibilidade de dar conta da singularidade, historicamente construída, no discurso/ato/dispositivo, ocasião de sua enunciação. Discurso que lhe dá as palavras para se dizer sujeito onde (e como) quer que assim se reconheça, no mesmo ato em que desconhece a sua historicidade. 


\section{Marlene Guirado}

\section{Retomar os começos é preciso}

Neste declarado esforço de explicitação dos pressupostos de nossa estratégia de pensamento, talvez tenhamos perdido de vista a clareza da exposição, e o leitor, por sua vez, talvez já tenha se perguntado o pra quê de tantas palavras.

Tudo começou com a disposição de justificar uma modalidade de fazer estudos de caso e/ou psicodiagnósticos numa perspectiva que considerasse o referencial teórico, ou melhor e mais corretamente falando, os discursos que informam nosso pensamento e nossos procedimentos. Como não há possibilidade de produzir o que quer que seja fora de algum discurso, dedicamo-nos a esclarecer as bases daquele que tece a proposta de um estudo institucional de caso.

A idéia primeira é que conceitos/procedimentos implicam-se, mediatamente, nos resultados a que se chega e que isto se faz de modo absolutamente alheio à nossa vontade e consciência, pelo simples fato de reconhecermos nossas práticas psicológicas como naturais e legítimas, como obviamente afeitas àquilo que se quer conhecer e/ou avaliar. E, pelo fato de desconhecermos sua relatividade, seu caráter instituído.

Se enveredamos por rebuscadas proposituras de formas de pensar o sujeito, é porque fazemos Psicologia numa aproximação com a Psicanálise e por ela damos voz a um sujeito psíquico, ao fato psíquico, como costumamos dizer. E, como pensar o psiquismo na fronteira com outros saberes e outras áreas do conhecimento?

Tendo esses aspectos em vista, demos destaque às seguintes formulações: todo discurso é ato e supõe, concretamente, um jogo de expectativas entre parceiros; estas expectativas, uma vez atendidas, tendem a se estabilizar, legitimar falas e posições bem como tendem a favorecer repetições confirmadoras. Foi assim traçada a íntima relação entre discurso e instituição. Há ainda que se arrematar o dito, no entanto: ao fazer Psicologia em qualquer uma de suas especialidades, fazemos instituições e contribuímos para a definição de seus contornos como disciplina do conhecimento, a partir de 


\section{O Caso do Psicodiagnóstico: um Estudo Institucional}

um lugar que não está fora do discurso, mas que, muito pelo contrário, nele e por ele se enuncia e se repete. Assim, como que num único golpe, podemos dizer que ao fazer um psicodiagnóstico, enunciamos do interior de um discurso que faculta, ao mesmo tempo e ato, os procedimentos de avaliação e o psiquismo que com eles se descortina. É por essa razão, e por essa perspectiva, que pudemos afirmar que os resultados de um psicodiagnóstico falam, antes de tudo, do próprio diagnóstico como discurso.

Posto isso, liberamo-nos para prosseguir com as decorrências de pensar dentro dos limites do recorte de nossa proposta.

\section{A rigor, todo psicodiagnóstico é um estudo institucional.}

A decorrência mais imediata é essa de que todo diagnóstico psicológico é sempre um estudo institucional. Ainda que não tenhamos a menor notícia consciente disto. Seja ele feito como parte de um processo terapêutico, ou com vistas a ele, num consultório particular à demanda de alguém que procura o profissional com essa finalidade, quer seja o atendimento oferecido como parte de um conjunto de serviços educacionais, de saúde, ou institucionais de outra ordem.

Por ora, vamos nos deter na situação do consultório, para facilitar a ordem de apresentação das idéias.

Temos nessa situação, paradoxalmente, a ocasião mais esclarecedora e menos esclarecida do que vimos afirmando.

Por um lado, é uma ocasião esclarecedora, por excelência, dos pressupostos teóricos que apresentamos. Acompanhemos o raciocínio: estando o profissional diante de seu cliente-paciente que lhe demandou por si ou por terceiros, o estudo ou avaliação, ouvirá o que lhe é falado, com os termos que tem para ouvir, isto é, vai ouvir como queixa/fantasia/destrutividade/voracidade/paranóia/reparação/culpa/inveja, ou ainda, como demanda/desejo/necessidade/fantasma/discurso imaginário/palavra plena, e assim por diante. No relato que um terapeuta faça sobre o atendimento, podemos 


\section{Marlene Guirado}

identificar imediatamente seu alinhamento a uma ou outra orientação psicanalítica; isto é, podemos identificar o discurso que instrumentou sua escuta. Claro que este é um jogo até certo ponto divertido e possível se pudermos pensar e operar à distância de qualquer uma delas. Claro também que, apesar da existência concreta de um paciente em tal ou qual situação, o que dele se fala, fala mais da escuta de quem o ouviu...

Por outro lado, e se formos coerentes com o que se afirmou acima, o atendimento em tal situação é aquele que mais "naturalmente” conduz o profissional a conclusões que respiram a obviedade dos reconhecimentos instituídos e à certeza de aproximação de uma verdade sobre o dito/dizer inconsciente. E essa consciência pouco esclarecida se deve, em grande parte, ao fato de ser o consultório o locus onde historicamente se constituiu a Psicanálise, instituição-matriz da maioria das terapias. Para demonstrá-la, basta lembrar da estranheza que expressam aqueles que, provenientes de comunidades discursivas psicanalíticas diferentes, ouvem os diagnósticos feitos por seus pares de profissão e ímpares de filiação teórica.

Dizendo desta forma, parecemos sugerir que nenhum diagnóstico é possível e que nenhum conhecimento se pode ter da realidade de um paciente. Rigorosamente a partir do recorte aqui proposto, não é mesmo! Mas que se tranqüilize nosso oponente: se não é possível para você, igualmente não o é para mim ou para ninguém.

Jogamos tudo para o alto, então? De forma alguma. Isso porque, se essa constatação da igualdade de pontos de partida pode acalmar os ânimos e aniquilar um confronto, não deveria acalmar nem aniquilar nossa disposição para um árduo trabalho de escuta. Pelo contrário, ela (a constatação do sermos todos iguais no ponto de largada, ou diante de Deus, como se prefira) nos coloca na posição de construir uma ética do atendimento, em outras bases. Agora, então, as bases de uma escuta que acompanha o dizer do paciente, no modo sua organização, nas cenas enunciativas construídas, considerando que fala para nós, naquela cenografia e naquele gênero de discurso de um atendimento, de um diagnóstico ou de uma avaliação; uma escuta que 


\section{O Caso do Psicodiagnóstico: um Estudo Institucional}

considera não só o discurso do paciente como também o do profissional, para dizer de qualquer sentido produzido naquela relação.

Então, se distraidamente e como quem nada quer, assim fazemos a instituição do conhecimento psicológico a cada atendimento, todo psicodiagnóstico é um estudo institucional.

\section{Na transferência, a construção de sentidos para o discurso em análise}

Talvez tenhamos chegado a um ponto em que sejam necessárias mais algumas considerações para que possamos permanecer no plano da indagação sobre como e até onde se pode produzir na fronteira de discursos. Na pressa de fechar um argumento, deixamos temporariamente suspensa a afirmação segundo a qual os sentidos que habitualmente tendemos a pensar sejam determinados pelo inconsciente do paciente, deveriam antes ser pensados como produzidos na relação de fala, no discurso do atendimento que supõe também as palavras que informam a escuta do psicólogo. Usamos o termo relação, ou, para fins desta escritura, relação de fala. Ora, ele abre um atalho de retorno à Psicanálise, num de seus conceitos mais sagrados e diferenciadores: relação transferencial, ou simplesmente, transferência. Nele está mais uma possibilidade de fundamentar nossa proposta de estudo institucional... de caso... pensado; isto é, por opção ética de fazer Psicologia. Vamos a isso, situando brevemente a transferência tal como pensada por Freud, para depois indicar uma reconsideração das idéias de contexto e análise da lingüística que tomamos como um dos pilares de nossa compreensão.

No historial de Dora (Freud, 1905/1969), em Repetir, Recordar... (Freud, 1914/1969) e em Observações Sobre o Amor... (Freud, 1915/1969), Freud situa a transferência como uma nova edição de impulsos e fantasias, como estruturas mentais inconscientes que se repetem e se atualizam, quando há circunstâncias externas favoráveis que se prestem a substituir uma figura anterior significativa para a pessoa.

Num destaque confessadamente interessado do texto freudiano, podemos dizer que: como uma reedição de afetos e atitudes, apagados da me- 


\section{Marlene Guirado}

mória e agidos no presente à revelia da consciência da repetição, a transferência se faz cena em ato. E é com esse destaque que aproximamos o conceito do recorte com que trabalhamos (Guirado, 2000).

Deixando em suspenso a determinação pulsional do movimento psíquico, damos foco ao caráter de encenação que se atribui aos atos-de-fala transferenciais. Assim, na qualidade de analistas cabe-nos acompanhar as cenas que se enunciam (como se organiza a fala, portanto), considerando aí, lugares atribuídos e assumidos por aquele que nos fala, no contexto particular e concreto daquele atendimento, com as expectativas que buscam estabilização, inclusive na fala do próprio analista.

A cena enunciativa, portanto, como conceito, estende-se para dar conta do lugar concreto do analista com as expectativas que ele também desenvolve no contexto daquela relação, bem como para dar conta do lugar que a ele delega o paciente nas repetições que faz de situações outras para aquela do atendimento. Portanto, enquanto ouvimos o que alguém nos fala de si ou de terceiros, produzem-se sentidos que não se constituem apenas como reedições, na sombra de um passado, mas também e articuladamente, na sombra do discurso que ora se faz. Nessas reproduções todas, a produção de sentidos que, desse modo, se dirão transferenciais.

Se o contexto ou a cenografia for um atendimento em consultório particular, identificam-se com mais facilidade os vetores da produção de sentidos. Mas, se o contexto for o de uma outra instituição que supõe entre suas práticas, mais ou menos dominantes, a Psicologia e/ou a Psicanálise, como por exemplo, um Centro de Atendimento Psicossocial ou Psiquiátrico, ou ainda, um Hospital ou um Centro Educacional, as dificuldades se multiplicam pelo entrecruzamento das práticas sociais em questão, pelas superposições de lugares instituídos, pelo jogo de forças e de dominância das instituições que atravessam um aparentemente simples atendimento. E aí, mais do que nunca, vem em nosso socorro a possibilidade de pensar com o conceito de transferência, nessa reinterpretação dele que vimos propondo.

É o que faremos a seguir. 


\section{No olho do furacão: a Psicologia possível no entrecruzamento de ins- tituições}

Imaginemos um psicólogo que trabalhe numa instituição de saúde como um Caps, um hospital, ou um centro de atendimento terapêutico. A relação dele com o cliente que atenderá, ou atende, é atravessada por um consistente - e nada evidente - cruzamento de práticas sociais diversas: de um lado, o serviço público ou particular de saúde com os lugares e expectativas ali geradas a respeito de o que é o atendimento oferecido, dos profissionais que atendem e da clientela que demanda atendimento; de outro lado (para dizer só de dois lados), as profissões que prestam o serviço e suas diferentes orientações, o que supõe, também, um jogo particular de lugares e de expectativas entre o profissional e a clientela.

Continuemos imaginando nosso protagonista, mais especificamente, num Caps: seu lugar como psicólogo é a resultante de ser psicólogo num serviço público (com tudo o que isso implica), de estar em uma relação com o psiquiatra (técnico-rei nas instituições de saúde mental), de professar a orientação x ou y em Psicologia e, como tem acontecido, de fazer parte de um projeto específico de implantação da Psicanálise como alternativa às técnicas desumanas da psiquiatria clássica.

Dá ainda para continuar imaginando? Dá... Nosso personagem, agora já quase laureado como herói, tem algumas possibilidades de resolver a iminência de impasses. A primeira é tomar a saída da negação básica da tensão e trabalhar como quem reconhecesse que todo trabalho renderá suor ao rosto e "vamos que vamos", ora mais ora menos animado. A segunda possibilidade é tomar a saída da crítica ácida à estrutura do serviço público, e "fazer só o que dá” em meio a uma carência tão generalizada; ou alternar mobilizações políticas fora do espaço institucional com utilização, dentro dele, de recursos técnicos disponíveis, sem muita alteração, porque, "afinal, o que importa não é a técnica”. A terceira, é sentir-se literalmente num hospício no qual "foi para o espaço" a condição de entendimento e comunicação e tomar a saída da licença saúde/insalubridade. A quarta é encarar as dificuldades de ser psicólogo nessas condições e tomar a saída de "por ordem na bagunça", 


\section{Marlene Guirado}

quer pela via da re-organização das relações entre os profissionais, quer pela via da re-estruturação do cotidiano dos usuários, quer pelos dois caminhos. A quinta possibilidade é intuir que a saída anterior exigiria um cacife maior para a nossa Psicologia nesse tipo de instituição, e tomar a saída de "equilibrar-se em fios de alta tensão”, considerando essa tensão como parte da produção possível, como ocasião dela, inclusive.

O leitor deve ter notado a ênfase favorável à quinta saída. Mas que note também as restrições que ela indica, na medida em que pressupõe um inevitável enredamento do psicólogo, no conjunto das práticas de atendimento. Afinal, seu trabalho só se exerce a partir de um dos lugares nessa rede de relações, no interior de um discurso que se tece absolutamente implicado nos procedimentos de um serviço que assim se faz atendimento em saúde mental. Sua vantagem sobre as demais saídas está, no entanto, na possibilidade de supor, de ponto de partida, a relatividade de sua ação ao contexto. E, que se acrescente: esta rachadura nos efeitos de reconhecimento/desconhecimento, nos efeitos imaginários de tais práticas está longe de ser uma conquista que se faça vez por todas; pelo contrário, é exercício constante e constitutivo de seu ofício. Aliás, aí está a tensão particular que atravessa seu lugar. Nela e por ela, se configurará a singularidade possível deste sujeito/psicólogo, sobretudo na relação com o sujeito/usuário daquele serviço.

Montadas as cenas e as preferências, a invenção do protagonista da quinta saída ilustra, o que chamamos, com Foucault, produção de subjetividade e modo de subjetivação; ilustra, ainda, o que nomeamos metáfora do sujeito-dobradiça, para poder afirmar a dimensão institucional do psiquismo. Em tais práticas, onde ele toma um dos assentos, produzem-se subjetividades/sujeitos, por procedimentos/discurso/dispositivo/ato, nos diferentes lugares da rede de relações, que assim instituem efeitos imaginários de reconhecimento/desconhecimento, a respeito do si e do fazer, na repetição que reedita em outras bases a história de cada um. Não é difícil pensar que isto acontece tanto com o nosso personagem psicólogo como quanto com seu hipotético cliente. São esses os modos de subjetivação possíveis por aquelas práticas discursivas, por aquela rede de relações concretas. 
É assim que o desenho geral da subjetividade-efeito, dessa forma particular de se fazer uma instituição de saúde, é um espetacular caleidoscópio, cujos matizes se definem pela composição de práticas dominantes e dominadas, pelo exercício de correlação de forças no jogo de poder/resistência ali configurados.

Se o personagem psicólogo que criamos prosseguir com seu roteiro e texto, produzirá, como uma das práticas dessa instituição, um diagnóstico que, no limite do possível, delineará o conjunto das relações do Caps, partindo de um foco: o que de si e dos seus outros falar o usuário do serviço, seu paciente

\section{Na atenção à dimensão institucional do fazer, a regra de ouro.}

Alguém poderia considerar um tanto vaga a estratégia de pensar/fazer a Psicologia e o psicodiagnóstico aqui proposta. Poderia, também, perguntar sobre procedimentos ou recursos técnicos específicos para um estudo de caso nessa perspectiva institucional. A consideração e a pergunta são legítimas. No entanto, as respostas permanecerão, neste plano de propositura, ainda indicadora de caminhos. Até porque, a questão não é a de inventar novas técnicas, mas a de garantir, exatamente, uma perspectiva de posicionamento e de leitura ao fazer o atendimento. Para sermos coerentes, é com isso que se terá um procedimento diferenciado.

Mais: é todo o discurso diagnóstico que se altera, porque se tece, em ato, num fazer que se põe nessa perspectiva. Ou então, não teríamos que afirmar, em meio a tanto esforço, a idéia de discurso como instituição/dispositivo/ato.

Tudo pode radicalmente se alterar se mudamos as lentes da máquina. Porque mudam as expectativas do lado de quem atende no lugar de agente da Psicologia. A relação se faz outra a partir daí. O que procura o atendimento terá sua demanda, isto é, sua expectativa reagida por um contexto concreto também outro. 


\section{Marlene Guirado}

A mágica, se assim parece o jogo todo, é essa reconstituição da cena enunciativa dos parceiros como uma outra ordem analítico-diagnóstica. E os efeitos dela, os resultados, falarão a diferença.

Tomemos como situação exemplar, a entrevista psicológica, procedimento reconhecidamente afeito ao nosso ofício. Ela nos servirá, agora, para esclarecimentos adicionais.

Como seria fazê-la no interior dessa perspectiva? Deixando de lado as finalidades específicas que poderiam originalmente ter, o primeiro cuidado a ser tomado é o de pensá-la como ocasião da produção de conhecimento naquela instituição de saúde em particular, naquele contexto concreto. Para começar, isto implica considerar em que ponto do atendimento acontece a entrevista, tendo em vista que expectativas já foram criadas por e em situações anteriores, com outros profissionais-agentes institucionais. Há serviços de recepção e de triagem, onde o paciente já contou sua história e demanda, onde os problemas de que se queixa já receberam algum tipo de acolhida e, mesmo, uma pré-avaliação que lhe valeram o encaminhamento para o setor de Psicologia. Num Caps, provavelmente, já tenha "passado” por psiquiatra e assistente social, inclusive. A pessoa que está diante do psicólogo, portanto, é já um cliente daquela instituição e o que lhe falar bem como o que ouvir, passará pelo crivo dos sentidos que a breve história naquele lugar tiver articulado à sua história pessoal e aos motivos que o levaram até lá. Qualquer transferência que se possa delinear supõe, necessariamente, essa tessitura afetiva e o psicólogo faz parte dela. Desse modo assentados os interlocutores, inicia-se aquela entrevista em particular, e tudo o que se disser terá, inconteste, a ver com tais posições. Em decorrência, não será mais possível atribuir sentidos, apenas, a uma realidade psíquica endógena. As razões e motivos do paciente, usuário do serviço, já ganharam outros sentidos.

Com esse pressuposto, a entrevista com o psicólogo deveria ser conduzida de maneira a permitir que se configurassem as representações/encenações relativas aos lugares que o entrevistado vê-se ocupando naquela e em outras relações, o lugar que atribui aos outros, as expectativas que constrói para sua vida e seus vínculos, incluindo o que espera daquele 


\section{O Caso do Psicodiagnóstico: um Estudo Institucional}

atendimento público (Guirado, 2000, 2004). Isto também é válido no caso de se entrevistarem pais ou responsáveis pela pessoa que ora se põe aos cuidados da instituição. Um roteiro simples que a leve a falar de si, tanto no que diz respeito aos motivos imediatos da procura do serviço, ou do que a aflige no momento, como quanto no que diz respeito às situações cotidianas e relações que lhe são significativas, ou ao que gosta e não gosta de fazer, e assim por diante. O importante é por a pessoa a contar de si, de sua história e de como e porque chegou até lá.

É necessário que se reafirme que a escuta deve evitar as interpretações psicológicas imediatas, para abrir espaço à atenção ao modo como se organiza a fala, naquele contexto para aquele profissional, naquele ponto do atendimento que a instituição oferece. Aí está o berço dos sentidos e do traçado diagnóstico possível.

Não foi arbitrária a escolha de estender os esclarecimentos a partir da entrevista. Na verdade, ela está na base de todos os procedimentos nos atendimentos psicológicos. Se com ela explicamos e entendemos a diferença de operar com estudos institucionais de caso, podemos entender e explicar de forma exemplar o que ora se propõe como modo de fazer Psicologia como instituição e nas instituições.

\section{Para terminar, é preciso continuar pensando}

Servimo-nos, no decorrer do presente texto, de metáforas como organizadores de conceitos; servimo-nos de cenas hipotéticas como situação concreta a elucidar palavras às vezes duras e pouco esclarecedoras. Com isso, em nome do rigor de pensar/fazer avaliações e psicodiagnósticos ao bem de quem os demanda (os pacientes da clínica, os usuários-pacientes de instituições de saúde), podemos ter parecido, de um lado, conceitualmente pouco rigorosos e, de outro, pouco informativos nas indicações de como proceder. No entanto, fomos até o limite do possível para um trabalho escrito, como este, com a pretensão de, ao mesmo tempo, apresentar e fundamen- 


\title{
Marlene Guirado
}

tar uma proposta que escapa aos padrões habituais, consagrados por repetições incontáveis da prática da Psicologia e da Psicanálise.

Há um engessamento característico nesses exercícios de argumentação. Mas ele se perde ou se dilui, se considerarmos as diversas ocasiões em que trabalhos concretos foram desenvolvidos com essa perspectiva quer no plano da pesquisa, quer nas intervenções diretas, na clínica e em outras instituições.

São essas ocasiões que nos fazem continuar pensando e encarando os desafios de produzir na esteira de uma espécie de resistência à fossilização de nossas práticas e de nosso conhecimento.

Guirado, M. (2005). Psychodiagosis case: an institutional study. Psicologia USP, 16 (4), 11-32.

\begin{abstract}
Psychodiagnosis is a recurrent case study practice in psychology; independently of being done in private offices, schools, hospitals, ambulatory and/or educational institution. The present article discuss the institutional dimension of that practice, when treated as a disposal that legitimize more and more its object: the psyche knowledge of those who subject themselves to the psychologist services. Such discussion comes from the highlight of concepts like speech, individual, institution and analysis, that were taken on the psychoanalysis fields and on the analysis of concrete institutions. That articulation makes possible a case study that considers the institutional context of the diagnosis. Finally, a proposal is made: how to proceed in a case study that assumes the constitutive strench of this context on the results of a client/patient psychodiagnosis of the psychologist
\end{abstract}

Index terms: Psychodiagnosis. Psychotherapeutic processes. Residential care institutions.

Guirado, M. (2005). Le cas du psychodiagnostic : une étude institutionnelle. Psicologia USP, 16 (4), 11-32. 


\section{O Caso do Psicodiagnóstico: um Estudo Institucional}

Résumé: Le psychodiagnostic est une pratique récurrente d'étude de cas en psychologie, qu'il soit effectué dans des cabinets médicaux privés, des écoles, des hôpitaux, des infirmeries et/ou des institutions para-éducatives. Le présent article aborde la dimension institutionnelle de cette pratique, dans la mesure où il s'agit d'un outil qui légitime, de plus en plus, son objet : la connaissance du psychisme de celui qui s'expose aux services du psychologue. Cette discussion part de la distinction de concepts tels que discours, sujet, institution et analyse, pris dans les domaines de la psychanalyse et de l'analyse d'institutions concrètes, pour configurer une possibilité d'étude de cas qui considère le contexte institutionnel (ou dans lequel il s'est effectué) du diagnostic. Il est, enfin, proposé une façon de procéder à une étude de cas qui suppose la force constitutive de ce contexte sur le résultat du psychodiagnostic d'un client/patient du psychologue.

Mots clés: Psychodiagnostic. Processus psychoterapeutique. Institutions de sauté.

\section{Referências}

Birman, J. (1999). Mal-estar na atualidade: a psicanálise e as novas formas de subjetivação. Rio de Janeiro: Civilização Brasileira.

Foucault, M. (1979). Microfísica do poder (R. Machado, trad.). Rio de Janeiro: Graal.

Foucault, M. (1990). Tecnologias del yo. Barcelona, España: Paidós. (Trabalho original publicado 1988)

Foucault, M. (1996). A ordem do discurso. São Paulo: Loyola. (Trabalho original publicado em 1970)

Freud, S. (1969). Fragmento da análise de um caso de histeria. In S. Freud, Edição standard brasileira das obras psicológicas completas de Sigmund Freud (J. Salomão, trad., Vol. 7, pp. 15-116). Rio de Janeiro: Imago. (Trabalho original publicado em 1905)

Freud, S. (1969). O mal-estar na civilização. In S. Freud, Edição standard brasileira das obras psicológicas completas de Sigmund Freud (J. Salomão, trad., Vol. 21, pp. 75-279). Rio de Janeiro: Imago. (Trabalho original publicado em 1930)

Freud, S. (1969). Observações sobre o amor transferencial (novas recomendações sobre a técnica da psicanálise III). In S. Freud, Edição standard brasileira das obras psicológicas completas de Sigmund Freud (J. Salomão, trad., Vol. 12, pp. 207-223). Rio de Janeiro: Imago. (Trabalho original publicado em 1915) 


\section{Marlene Guirado}

Freud, S. (1969). Recordar, repetir e elaborar (novas recomendações sobre a técnica da psicanálise II). In S. Freud, Edição standard brasileira das obras psicológicas completas de Sigmund Freud (J. Salomão, trad., Vol. 12, pp. 191-203). Rio de Janeiro: Imago. (Trabalho original publicado em 1914)

Galvão, L. F. (2000). Práticas alternativas? Uma leitura institucional da questão. Dissertação de mestrado, Instituto de Psicologia, Universidade de São Paulo, São Paulo.

Guilhon Albuquerque, J. A. (1978). Metáforas da desordem: o contexto social da doença mental. Rio de Janeiro: Paz e Terra.

Guirado, M. (1995). Psicanálise e análise do discurso: matrizes institucionais do sujeito psíquico. São Paulo: Summus.

Guirado, M. (2000). A clínica psicanalítica na sombra do discurso: diálogos com aulas de Dominique Maingueneau. São Paulo: Casa do Psicólogo.

Guirado, M. (2004). Instituição e relações afetivas: o vínculo com o abandono (ed. rev. e ampl.). São Paulo: Casa do Psicólogo.

Lerner, R. (1999). Instituições: a psicanálise na ordem do discurso de agentes de saúde mental. Dissertação de mestrado, Instituto de Psicologia, Universidade de São Paulo, São Paulo.

Maingueneau, D. (1987). Novas tendências em análise do discurso (F. Indusky, trad.). Campinas, SP: Editora da Universidade Estadual de Campinas.

Maingueneau, D. (1996). Introdução à lingüística (L. Baptista, trad.). Lisboa: Gradiva.

Souza, A. M. O. (2003). Loucura em cena: a “Ambiência” como espaço informal de tratamento em um Centro de Atenção Psicossocial. Dissertação de mestrado, Instituto de Psicologia, Universidade de São Paulo, São Paulo.

Vechi, L. G. (2002). A primeira internação na ordem do discurso de agentes de saúde mental de hospital-dia. Dissertação de mestrado, Instituto de Psicologia, Universidade de São Paulo, São Paulo.

Veiga L. G. (2000). A instituição da psicanálise no discurso de psicanalistas. Pesquisa de Iniciação Científica do Instituto de Psicologia da Universidade de São Paulo. Texto não publicado.

Recebido em: 09.09.2005

Aceito em: 31.10.2005 